\title{
Update on Liver Failure Following Hepatic Resection: Strategies for Prediction and Avoidance of Post-operative Liver Insufficiency
}

\author{
Amir A. Rahnemai-Azar ${ }^{1}$, Jordan M. Cloyd ${ }^{2}$, Sharon M. Weber ${ }^{1}$, Mary Dillhoff ${ }^{2}$, Carl Schmidt ${ }^{2}$, \\ Emily R. Winslow ${ }^{1}$ and Timothy M. Pawlik*2 \\ ${ }^{1}$ Department of Surgery, Division of Surgical Oncology, University of Wisconsin Hospital, Madison, WI, USA; ${ }^{2}$ Department of \\ Surgery, Division of Surgical Oncology, The Ohio State University Wexner Medical Center, Columbus, OH, USA
}

\begin{abstract}
Liver resection is increasingly used for a variety of benign and malignant conditions. Despite advances in preoperative selection, surgical technique and perioperative management, posthepatectomy liver failure (PHLF) is still a leading cause of morbidity and mortality following liver resection. Given the devastating physiological consequences of PHLF and the lack of effective treatment options, identifying risk factors and preventative strategies for PHLF is paramount. In the past, a major limitation to conducting high quality research on risk factors and prevention strategies for PHLF has been the absence of a standardized definition. In this article, we describe relevant definitions for PHLF, discuss risk factors and prediction models, and review advances in liver assessment tools and PHLF prevention strategies.

Citation of this article: Rahnemai-Azar AA, Cloyd JM, Weber SM, Dillhoff M, Schmidt C, Winslow ER, et al. Update on liver failure following hepatic resection: strategies for prediction and avoidance of post-operative liver insufficiency. J Clin Transl Hepatol 2018;6(1):97-104. doi: 10.14218/JCTH.2017.00060.
\end{abstract}

\section{Introduction}

Liver resection is the cornerstone of treatment for many benign and malignant liver tumors. Recent advances in our understanding of liver anatomy, high-quality 3D imaging, systemic chemotherapy, and surgical technique have broadened the indications for liver resection, permitting resection of tumors that have traditionally been considered unresectable. ${ }^{1-3}$ At the same time, improvements in patient selection,

Keywords: Complication; Hepatectomy; Liver failure; Liver resection; Prevention; Risk models.

Abbreviations: ALPPS, associating liver partition and portal vein ligation for staged hepatectomy; CRLM, colorectal liver metastasis; CT, computed tomography; DM, diabetes mellitus; $\mathrm{DH}$, degree of hypertrophy; FLR, future liver remnant; GSA galactosyl human serum albumin; ICG, indocyanine green; INR, international normalized ratio; ISGLS, International Study Group of Liver Surgery; MRI, magnetic resonance imaging; PHLF, posthepatectomy liver failure; PT, prothrombin time; $P V E$, portal vein embolization; PVL, portal vein ligation; R-15, retention rate at 15 minutes; TLV, total liver volume.

Received: 15 September 2017; Revised: 22 October 2017; Accepted: 23 October 2017

*Correspondence to: Timothy M. Pawlik, The Urban Meyer III and Shelley Meyer Chair for Cancer Research, Department of Surgery, Wexner Medical Center, Ohio State University, 395 W. $12^{\text {th }}$ Ave., Suite 670 , Columbus, $\mathrm{OH} 43210$, USA. Tel: +1-614 293 8701, Fax: +1-614 293 4063, E-mail: Tim.Pawlik@osumc.edu future liver remnant (FLR) augmentation and perioperative care have enabled the safer application of liver surgery. Posthepatectomy liver failure (PHLF), however, remains as a major source of morbidity and mortality following major liver resection.

The incidence of PHLF ranges from $1 \%$ to $34 \%$, depending on author definition, extent of hepatic resection, and characteristics of the study population. ${ }^{4-6}$ Fortunately, a better understanding of risk factors for liver insufficiency as well as improvements in preventative strategies have resulted in a meaningful decrease in the incidence of PHLF throughout the past decade. Nevertheless, PHLF remains a dreaded complication due to its strong association with mortality and the lack of effective therapeutic options to manage it. In this article, we perform a systematic review of PHLF including recent advances in definition, risk factors and preventative strategies.

\section{Methods}

A systematic review of the literature was performed utilizing MEDLINE/PubMed and Web of Science databases in July of 2017. The MESH terms "liver failure", "liver insufficiency" and "hepatic failure" in combination with "liver surgery", "liver resection", "hepatectomy", "laparoscopic liver resection" and "laparoscopic hepatectomy" were searched in the title and/or abstract. The references of relevant articles were reviewed to identify additional eligible publications. The resulting Englishlanguage articles were subsequently reviewed for relevance.

\section{Definition}

In the past, the absence of a uniform definition of PHLF was the major limitation to the identification of patients at risk for liver failure-related mortality as well as effective research collaboration across institutions. Challenges to the creation of a single uniform definition of PHLF included variation in the extent of hepatic resection, discrepancies in the quality of preoperative liver function, and limited information on normal postoperative recovery of biochemical indices following liver resection. For these reasons and others, more than 50 different definitions for hepatic insufficiency have been proposed. ${ }^{7}$ In practice, the three most commonly used definitions of PHLF include the "50-50 rule", the "peak bilirubin $>7$ " rule and the International Study Group of Liver Surgery (ISGLS) definition (Table 1). 
Rahnemai-Azar A.A. et al: Prevention of post-hepatectomy liver failure

Table 1. Common definitions and predictive models for PHLF $^{7-9,16}$

\begin{tabular}{ll}
\hline Definitions & Description \\
\hline $50-50$ criteria & $\begin{array}{l}\text { Prothrombin time }>50 \% \text { of normal (INR }>1.7 \text { ) and serum bilirubin }>50 \mu \mathrm{mol} / \mathrm{L} \\
(>2.9 \mathrm{mg} / \mathrm{dL}) \text { on postoperative day } 5\end{array}$ \\
$\begin{array}{l}\text { Peak bilirubin }>7 \mathrm{mg} / \mathrm{dL} \\
\text { ISGLS }\end{array}$ & $\begin{array}{l}\text { Postoperative peak bilirubin }>7 \mathrm{mg} / \mathrm{dL} \\
\text { "Postoperatively acquired deterioration in the ability of the liver to maintain its synthetic, } \\
\text { excretory, and detoxifying functions, characterized by an increased INR and hyperbilirubinemia } \\
\text { on or after postoperative day 5" }\end{array}$ \\
$\begin{array}{ll}\text { Predictive models } \\
\text { MELD score }\end{array}$ & $\begin{array}{l}\text { Used for determining the mortality risk of patients with end-stage liver disease; calculated } \\
\text { based on serum creatinine, bilirubin, INR and dialysis status }\end{array}$ \\
Child-Pugh score & $\begin{array}{l}\text { Originally used to predict postoperative mortality among cirrhotic patients, and now more } \\
\text { commonly used for grading cirrhosis into three distinct classes; calculated based on bilirubin, } \\
\text { albumin, INR, ascites and encephalopathy }\end{array}$ \\
Hyder et al. & Risk score based on INR, bilirubin, creatinine and complication grade on postoperative day 3 \\
ALBI ${ }^{87}$ & Scoring system based only on preoperative albumin and bilirubin
\end{tabular}

Abbreviations: ALBI, albumin-bilirubin; INR, international normalized ratio; ISGLS, international study group for liver surgery; MELD, model for end-stage liver disease.

Balzan et al. ${ }^{8}$ introduced the "50-50 criteria", which is defined as prothrombin time (PT) $<50 \%$ (international normalized ratio $($ INR) $>1.7$ ) and serum bilirubin $>50 \mu / \mathrm{L}(>2.9 \mathrm{mg} /$ $\mathrm{dL}$ ) on postoperative day 5 . In the original study, those patients who met both criteria had a $59 \%$ incidence of in-hospital mortality compared to a $1.2 \%$ risk among patients who met neither criteria. While the sensitivity and specificity of in-hospital mortality using the "50-50 criteria" was $69.6 \%$ and $97.7 \%$, respectively, in the original cohort, subsequent validation studies have had mixed results. ${ }^{8-10}$ Later, Kim et al. ${ }^{11}$ would suggest modifying the " $50-50$ criteria" to a PT of $<65 \%$ and bilirubin of $>38 \mu \mathrm{mol} / \mathrm{L}(2.2 \mathrm{mg} / \mathrm{dL})$ to improve sensitivity.

Mullen et al. ${ }^{9}$ proposed a simplified definition of PHLF based only on a postoperative peak bilirubin of $>7 \mathrm{mg} / \mathrm{dL}$. Using a multi-institutional retrospective database of 1059 patients, peak bilirubin of $>7 \mathrm{mg} / \mathrm{dL}$ was the most powerful predictor of postoperative complications, major complications, mortality and PHLF-related mortality. Indeed, the authors reported an area under the curve, sensitivity and specificity of $0.98,93.3 \%$ and $94.3 \%$, respectively, for predicting PHLF-related mortality. Nevertheless, subsequent analyses have had mixed results in validating the efficacy of peak bilirubin as the sole defining criteria for PHLF.

While the advantage of the "50-50 criteria" and peak bilirubin $>7$ rule are their well-defined criteria and simplicity, agreement on a definition of PHLF that was applicable universally regardless of underlying liver function or extent of liver resection remained elusive. In 2011, the ISGLS convened a consensus conference to define PHLF as "a postoperatively acquired deterioration in the ability of the liver to maintain its synthetic, excretory, and detoxifying functions, which are characterized by an increased INR and concomitant hyperbilirubinemia on or after postoperative day $5^{\prime \prime}{ }^{7}$ In addition, the ISGLS also proposed a model for grading the severity of PHLF based on its impact on clinical management.

In addition to the most common definitions of PHLF, numerous predictive models have been generated based on pre- and postoperative clinical and biochemical characteristics, to predict PHLF-related morbidity and mortality. For example, the model for end-stage liver disease score and Child-Pugh score, both originally designed for grading the severity of end-stage liver disease, are two of the more wellknown scoring systems that have been validated for predicting PHLF. ${ }^{12-15}$ In addition, Hyder et al. ${ }^{16}$ used a multi-institutional cohort of 2056 patients who underwent liver resection to generate a composite integer-based risk score based on Clavien-Dindo complication grade and postoperative day 3 INR, bilirubin and creatinine. ${ }^{16}$ The composite prediction rule accurately predicted postoperative 90-day mortality, with an area under the curve of $0.93 .^{16}$

\section{Risk factors}

The identification of factors associated with PHLF is critical for the appropriate selection of patients to undergo liver resection as well as informing strategies for prevention of PHLF and postoperative mortality. In general, risk factors can be categorized as related to: patient comorbidities, primary liver function or perioperative events (Table 2).

\section{Patient-related factors}

Among patient-related factors, diabetes mellitus (DM) is one most closely linked to posthepatectomy morbidity and mortality. ${ }^{17-19}$ Little et al. ${ }^{18}$ in a study of 727 patients who underwent hepatic resection for colorectal liver metastasis (CRLM) showed that postoperative mortality was significantly higher in diabetic patients ( $8 \%$ vs. $2 \%$ in the non-diabetic group; $p<0.02$ ) and that PHLF was a leading cause of reported perioperative deaths. ${ }^{18}$ Furthermore, Huo et al. ${ }^{20}$ demonstrated that the long-term risk of developing hepatic insufficiency following liver resection in patients with hepatocellular carcinoma was higher among those with DM compared to non-diabetic individuals (3-year cumulative risk, $53 \%$ vs. $27 \%$ ). ${ }^{20}$ The association of DM with PHLF is presumably due to the importance of insulin in liver regeneration and hepatocyte function. ${ }^{21}$

Similarly, obesity and metabolic syndrome have been shown to be associated with higher rate of posthepatectomy complications and liver failure. ${ }^{19,22-24}$ In a retrospective analysis of 1021 patients with CRLM, obesity was independently associated with postoperative mortality (odds ratio $=1.64$, $95 \%$ confidence interval: $1.13-2.38$ ) as well as with a trend 
Table 2. Predictive factors associated with increased risk of PHLF

\begin{tabular}{l}
\hline Patient-related factors \\
Diabetes mellitus \\
Obesity \\
Metabolic syndrome \\
Malnutrition \\
Cholangitis \\
Age $>65$ years \\
Surgery-related factors \\
Increased intraoperative blood loss ( $>1200 \mathrm{~mL}$ ) \\
Intraoperative transfusion \\
Need for associated resection (e.g., vascular, colon) \\
Inadequate FLR (<20\% in case of normal underlying liver \\
function) \\
Extended liver resection ( $>50 \%$ of liver volume) \\
Longer operative time ( $>240$ minutes) \\
Major postoperative complications \\
Primary liver function \\
Cirrhosis \\
Steatohepatitis \\
Steatosis \\
Sinusoidal injury \\
Hyperbilirubinemia \\
Chemotherapy-associated liver injury \\
\hline
\end{tabular}

towards increased PHLF. ${ }^{22}$ Finally, Schindl et al. ${ }^{25}$ in a study of 104 patients with a normal synthetic liver function who underwent liver resection showed that a high body mass index was significantly associated with PHLF.

Some preclinical data have suggested a loss of liver function as well as regenerative capacity with increasing age; however, current clinical data regarding age as a risk factor of PHLF is controversial. ${ }^{26}$ While some studies identified older age as an independent predictor of worse postoperative outcome, other investigators have demonstrated the safety of liver resection in well-selected elderly patients. ${ }^{8,9,27,28}$ Nevertheless, populationbased studies using large administrative databases have found increased rates of postoperative morbidity and mortality among elderly patients undergoing hepatectomy, potentially due to higher rates of comorbidities and failure to rescue. ${ }^{29-32}$

\section{Primary liver function}

Underlying liver disease is one of the major determinants of hepatic regenerative capacity and is therefore closely associated with PHLF. Cirrhosis, as the end stage of hepatic injury and fibrosis, has been associated with rates of posthepatectomy mortality as high as $30 \%$, mainly due to PHLF. ${ }^{33,34}$ In addition, the rates of postoperative mortality are associated with the degree of cirrhosis. Importantly, animal models have elucidated the mechanisms by which cirrhosis contributes to reduced regenerative capacity and PHLF. ${ }^{35}$ Lesser degrees of parenchymal injury, as observed in patients with steatosis and steatohepatitis, have also been linked to worse outcomes following liver resection. ${ }^{36,37}$

An important contributor to underlying liver dysfunction is the hepatotoxic effect of systemic chemotherapy. Moreover, several studies have demonstrated that chemotherapyassociated liver injury is regimen-specific. ${ }^{38}$ For example, use of the topoisomerase inhibitor irinotecan has been linked to postoperative steatohepatitis, whereas use of the platinum oxaliplatin is associated with sinusoidal injury. Importantly, steatohepatitis has been independently associated with a significant increase in postoperative mortality. These findings have been corroborated by other institutional series and meta-analyses. ${ }^{39-41}$ With the increasing utilization of neoadjuvant therapy among patients undergoing liver resection, an understanding of the potential hepatotoxic effects of chemotherapy on liver function is critical.

Liver resection in the presence of jaundice has been associated with increased rates of PHLF and liver-related mortality. ${ }^{42}$ The underlying mechanisms appear to be related to cholestasis-induced ischemia/reperfusion injury as well as a reduction in antioxidant levels leading to increased inflammation. ${ }^{43}$ Impaired immune function, coagulopathy and malnutrition are also likely contributors to worse outcomes. Although still controversial, preoperative biliary drainage is typically recommended for patients presenting with hyperbilirubinemia prior to major hepatectomy, especially in the setting of cholangitis, malnutrition or hepatic insufficiency. ${ }^{44}$ Similarly, preoperative cholangitis has been found to be one of the strongest predictors of PHLF following major hepatectomy. ${ }^{45}$ Cholangitis likely impairs regenerative capacity of the liver and may lead to post-operative infectious complications. ${ }^{46,47}$

\section{Perioperative factors}

In addition to patient- and liver-related factors, issues pertaining to the surgery itself may contribute to the risk of PHLF. For example, both intraoperative blood loss and blood transfusion have been associated with PHLF. ${ }^{48-50}$ Excessive blood loss may lead to coagulopathy, hypotension and fluid shifts, which can predispose towards bacterial translocation. In addition, blood transfusion may have immunosuppressive effects. Major postoperative complications, such as biliary fistula or sepsis, may also contribute to PHLF, especially in the borderline liver or patient. It is important to note that PHLF may occur as the result of a combination of patient-, liver- and surgery-related factors such that a "second-hit" could further inhibit hepatocyte proliferation and lead to fulminant hepatic insufficiency.

An additional important surgery-related factor is avoiding "small-for-size" syndrome and ensuring adequate FLR volume and function. To be specific, the avoidance of liver failure following hepatic resection depends on the regenerative capacity of remaining liver tissue and its ability to maintain normal physiologic hepatic function for the body. Size is a surrogate for function and several studies have identified FLR size thresholds for predicting PHLF based on the presence of absence of liver dysfunction. In general, an FLR with at least two contiguous segments having adequate vascular inflow, outflow and biliary drainage is required. FLR of $<20 \%$ in chemotherapy-naïve patients, of $<30 \%$ in chemotherapytreated patients and of $<40-50 \%$ in cirrhotic patients are considered risk factors for PHLF. ${ }^{51,52}$

\section{Assessing liver function}

Since preoperative liver function is strongly associated with the incidence of PHLF and has important implications on surgical decision-making, methods of assessing baseline liver quality are critical. In general, preoperative liver function can be evaluated via a combination of traditional laboratory markers and clinical factors, liver volumetric analyses or functional tests. 
Rahnemai-Azar A.A. et al: Prevention of post-hepatectomy liver failure

\section{Traditional markers}

The ability of traditional laboratory markers, such as bilirubin, albumin, alkaline phosphatase, transaminases, PT/INR and others, to predict PHLF has been extensively reported on. While none have demonstrated perfect sensitivity and specificity by themselves, many are used in predictive scoring systems, such as the model for end-stage liver disease or Child-Pugh (Table 1). One important laboratory test not included in these scores is the platelet count. Thrombocytopenia may reflect poor synthetic capacity of the liver, underlying portal hypertension or another hematological disorder. Nevertheless, low platelet count is an important measure of liver function and predictive of PHLF. ${ }^{53}$ Likewise, preoperative imaging findings of portal hypertension including splenomegaly, ascites and gastroesophageal varices, as well as subtle signs of early cirrhosis, are indicative of significant liver dysfunction. ${ }^{54,55}$ Other traditional signs and symptoms of endstage liver disease should be carefully noted.

\section{Functional reserve estimation}

Indocyanine green (ICG) clearance test and ${ }^{99 m} \mathrm{Tc}$ diethylenetriamine-pentaacetic acid-galactosyl human serum albumin (GSA) scintigraphy are more advanced methods to evaluate the preoperative hepatic functional reserve, since both modalities provide more dynamic assessment of function compared to prior models. ${ }^{56,57}$ ICG is a water-soluble cyanine dye that tightly binds to plasma proteins and is exclusively cleared by the liver. ICG clearance parameters such as ICG plasma disappearance rate or retention rate at 15 minutes ( $R-15)$ have been introduced as indicators of underlying liver function and potentially correlated with PHLF. ${ }^{58-60}$

Fan et al. ${ }^{61}$ demonstrated that ICG R-15 levels above $14 \%$ were associated with a significant increase in posthepatectomy mortality. Imamura et al. ${ }^{62}$ used ICG R-15, in addition to ascites and serum total bilirubin level, to design a decision tree to determine the extent of safe hepatic resection in patients with a range of baseline hepatic reserve. Patients with normal bilirubin and without ascites could safely undergo extensive liver resection as long as ICG R-15 was below $10 \%$. $^{62}$ However, increasing ICG R-15 levels restricted the extent to which hepatectomy could be safely applied. With application of this model, their group were able to demonstrate zero mortality in a series of 1056 hepatectomies. Recently, the Japanese Liver Cancer Study Group incorporated ICG R-15 in a modified functional evaluation score-the liver damage grading system-as a more accurate tool for the assessment of hepatic functional reserve compared to Child-Pugh score alone. ${ }^{60}$

${ }^{99 m}$ Tc-GSA scintigraphy, which utilizes an analogue ligand of asialoglycoprotein that binds to asialoglycoprotein receptors on the hepatocyte cell membrane, has recently been introduced as a sensitive indicator of the liver functional reserve; several quantitative indices from the scintigraphy have been shown to correlate with risk of PHLF. Moreover, $99 \mathrm{~m}$ Tc-GSA scintigraphy can be integrated with SPECT/CT images in order to evaluate function of the FLR which may prove more useful than volume alone. ${ }^{63}$ Likewise, the development of liver-specific contrast studies like gadoxetic acidenhanced magnetic resonance imaging (MRI) has offered promising results in quantitative evaluation of hepatic function and are comparable to ICG R-15 and ${ }^{99 m}$ Tc-GSA scintigraphy. ${ }^{64}$ Costa et al. ${ }^{65}$ showed that a prediction model combining traditional clinical parameters and gadoxetic acid-enhanced MRI findings could significantly improve prehepatectomy risk assessment.

\section{Volumetric assessment}

Since FLR volume correlates with FLR function and risk of PHLF, a systematic assessment of liver volumetry during preoperative planning is critical, especially in the setting of baseline liver dysfunction or anticipated extended hemi-hepatectomy. Precise measurements of liver volume are also important given the substantial variability among patients. For example, Abdalla et $a l .{ }^{66}$ found that the contributions of the right and left hemilivers to total liver volume (TLV) ranged from $49 \%$ to $82 \%$ and $17 \%$ to $49 \%$, respectively, among 102 patients undergoing CT volumetry. Although ultrasound and 3D ultrasonography have been suggested as useful tools for volumetric assessment prior to major liver resections, their application has been somewhat limited, especially in most Western centers. Rather, CT and MRI are more universally accepted as the modalities of choice to calculate liver volume and estimate FLR. Using multidetector CT with 3D reconstruction software, the FLR volume is manually measured and then divided by the calculated TLV which is based on body surface area. ${ }^{67}$ This yields the standardized FLR, which provides an estimate of the percentage of the TLV that will remain after planned hepatic resection.

Using standardized liver volumetry, guidelines have been established for minimum FLR necessary to proceed with safe hepatic resection. In general, FLR $\geq 20 \%$ is considered the minimum safe volume for patients with normal liver function, while $\geq 30 \%$ is required for patients who received hepatotoxic chemotherapy and $\geq 40 \%$ is deemed necessary for patients with cirrhosis. ${ }^{68,69}$ For those patients who do not meet the minimum FLR thresholds, portal vein embolization (PVE) can be used to stimulate liver hypertrophy.

The liver's response to PVE also has important implications for postoperative hepatic function. For example, patients who experience $<5 \%$ degree of hypertrophy (DH) have an increased risk of PHLF and postoperative mortality. In addition, the kinetic growth rate, measured as the $\mathrm{DH}$ divided by number of weeks since PVE, is one of the strongest predictors of posthepatectomy outcomes with a kinetic growth rate $<2 \%$ being associated with significantly higher rates of PHLF. ${ }^{70}$ Finally, recent studies have demonstrated that extensive preoperative chemotherapy can induce hepatic atrophy, calculated as the percentage difference in manually measured TLV divided by the calculated TLV. Indeed, the degree of hepatic atrophy experienced during preoperative chemotherapy was found to be independently associated with PHLF and mortality. ${ }^{71}$

\section{Prevention and treatment}

Given the significant risk of mortality associated with PHLF as well as limited treatment options available, prevention of PHLF remains as the primary focus of current strategies. First, all efforts should be undertaken to preserve liver function, prevent worsening of liver dysfunction, and, when possible, reverse contributing factors. For example, weight loss, control of DM, aggressive management of other comorbidities and preoperative nutritional support should be encouraged. ${ }^{72}$ Patients with chronic hepatitis should be referred to a hepatologist for treatment.

Since more than 6 cycles of preoperative chemotherapy has been associated with chemotherapy-associated liver 
injury and worse posthepatectomy outcomes, avoidance of prolonged durations of preoperative systemic chemotherapy in patients with CRLM is prudent. Percutaneous biliary drainage of the FLR to prevent further liver atrophy and reverse jaundice should be strongly considered in hilar cholangiocarcinoma. Finally, in the postoperative setting, early recognition and intervention of complications such as postoperative hemorrhage, biliary fistula and sepsis may be important for reducing the incidence and severity of hepatic insufficiency.

In addition to preserving or improving liver function, modifications to perioperative technique are important for preventing PHLF. For example, an emphasis on parenchymalsparing approaches has resulted in preserved liver tissue, reduced rates of PHLF and no apparent worsening of pathological or oncologic outcomes. ${ }^{73-76}$ In addition, for patients with inadequate FLR volume to safely undergo major liver resection, significant advancements in FLR augmentation have occurred. Two such strategies are PVE and the associating liver partition and portal vein ligation for staged hepatectomy (ALPPS) procedure. ${ }^{68,77-80}$

Makuuchi et al. ${ }^{81}$ first proposed the use of PVE as a strategy to promote hypertrophy in patients with hilar cholangiocarcinoma who demonstrated inadequate FLR. As experience with PVE has increased and its safety profile improved over time, the application of preoperative PVE has been extended to other indications as well. ${ }^{77,78}$ PVE promotes growth of the FLR by redirecting portal flow to the FLR and increasing hypertrophy through clonal expansion of hepatocytes and in increase in production of hepatic growth factors (Figs. 1 and 2B). ${ }^{68,82}$

PVE is typically performed transhepatic, either via an ipsilateral or contralateral approach. A variety of embolization agents can be used including gelfoam, microspheres and coils. Usually more than $80 \%$ of patients will achieve $30-40 \%$ hypertrophy of FLR during a few weeks (4 to 6 weeks) following a successful PVE. For patients undergoing extended hepatectomy, the PVE can be extended to segment 4 in order to maximize the DH of the FLR. ${ }^{83}$ More recently, PVE has also been shown to mitigate the deleterious effects of hepatic atrophy that occur from extensive preoperative chemotherapy.

Portal vein ligation (PVL), instead of PVE, is an alternative consideration at the time of first-stage procedure for patients undergoing two-stage hepatectomy, but the amount of hypertrophy in response to PVL may be inferior to well-performed PVE (Fig. 2C). ${ }^{84}$ Hepatic vein embolization is another alternative that some investigators have suggested if portal vein occlusion fails. Though not widely adopted, ipsilateral occlusion of the hepatic vein may help induce incremental hypertrophy in the setting of a "failed" portal vein occlusion (e.g. PVE or PVL).

ALPPS is a novel approach to two-stage hepatectomy, in which a right PVL is combined with parenchymal transection and clearance of tumor in the FLR (Fig. 2D). The second stage is performed during the same hospitalization and involves completion of the hemi-hepatectomy. ALPPS has been associated with dramatic and rapid increases in FLR. For example, in its initial description, Schnitzbauer et al. ${ }^{85}$ reported a mean $74 \%$ increase in FLR volume over 9 days. Recent studies have reported FLR hypertrophy of $40-80 \%$ in an interval of $6-9$ days following first-stage of ALPPS. Nevertheless, given that ALPPS has been associated with significant rates of postoperative morbidity and mortality and that long-term oncologic safety is still unclear, it should be used in highly selected patients by experienced providers.

While it is best to avoid PHLF, some patients will develop it in the postoperative setting. The severity of the PHLF can be
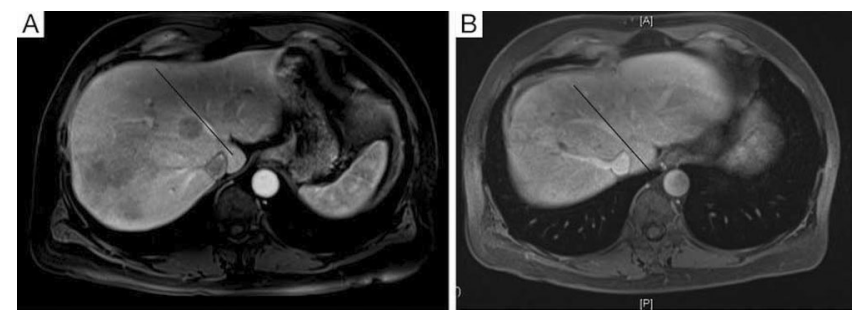

Fig. 1. (A) Pre-portal vein embolization of right lobe of liver to induce hypertrophy of left lobe of liver. (B) Six weeks post-portal vein embolization of right lobe of liver to induce hypertrophy of left lobe of liver. Line marks middle hepatic vein, dividing right and left hemi-livers. Used with permission. ${ }^{72}$

determined with laboratory exams, such as measurements of INR, platelets, ammonia, bilirubin and creatinine. Attempts to resuscitate the patient and avoidance of any "second-hit" complications, such as infection, are critical to provide the best chance of liver regeneration. In early stages of encephalopathy, ammonia levels should be followed and lactulose, polyethylene glycol or rifaximin used for treatment. While rescue orthotopic liver transplantation remains the most definitive treatment for PHLF, it is not universally available for many patients who develop PHLF.

\section{Conclusions}

In conclusion, PHLF is a significant cause of morbidity and mortality among patients undergoing major liver resection. Identification of patients at risk for PHLF permits an opportunity to implement evidence-based preventative strategies. Recent improvements in our understanding of liver volumetry,
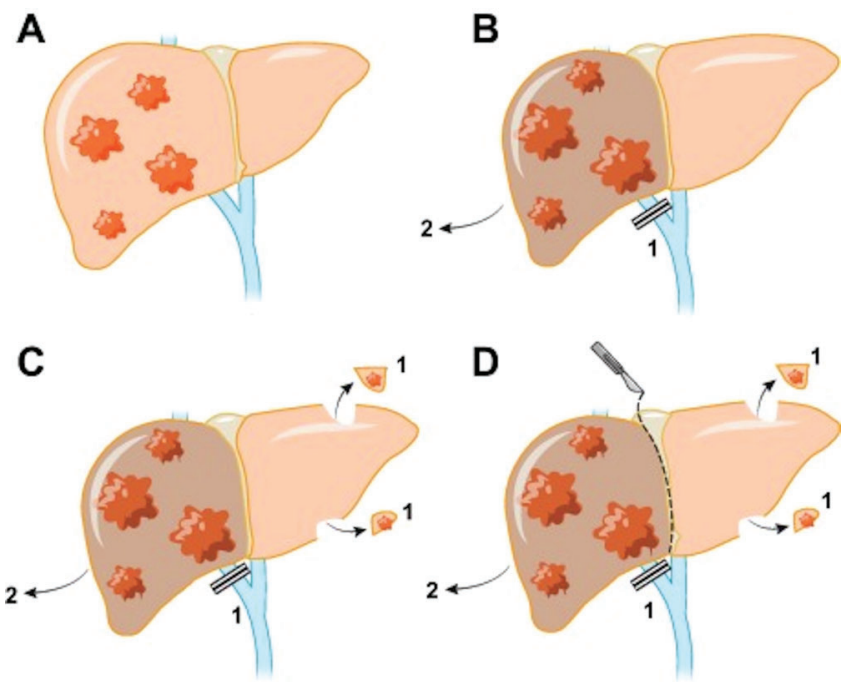

Fig. 2. Visualization of pre- or perioperative interventions and their effect on liver remnant volume. (A) Malignant liver disease. (B) Embolization/ligation of the right portal branch, (1) resulting in atrophy of the right hemi-liver and compensatory growth of the left hemi-liver, which can be removed when appropriate hypertrophy has been achieved (2). (C) Removal of tumours from the left hemi-liver and occlusion of the right portal branch (1). After 4-6 weeks, the volume of the left hemi-liver is increased and the right hemi-liver can be removed (2). (D) Removal of tumours from the left hemi-liver, in situ splitting of the hemi-livers, and simultaneous ligation of the right portal vein branch (1). After 1 week, augmented hypertrophy of the left hemi-liver permits removal of the right hemi-liver (2). Used with permission. ${ }^{86}$ 
functional hepatic imaging and risk scoring systems have allowed for more sophisticated and accurate preoperative risk assessment. In addition, improvements in FLR augmentation, including PVE and ALPPS, have expanded the application of major liver resection and improved its inherent safety profile. Future studies should aim to enhance understanding of the mechanisms and risk factors for PHLF, develop novel methods of improving both the volume and function of the FLR, and ultimately to develop more effective strategies for treating this challenging complication when it occurs.

\section{Conflict of interest}

The authors have no conflict of interests related to this publication.

\section{Author contributions}

Conception of study objectives and/or design, collection of data, analysis of data, interpretation of findings, drafting of the article (AARA), collection of data, analysis of data, interpretation of findings, drafting of the article, revising the article for important intellectual content (JMC), conception of study objectives and/or design, interpretation of findings, revising the article for important intellectual content (SMW), collection of data, analysis of data, interpretation of findings (MD), collection of data, analysis of data, interpretation of findings (CS), collection of data, analysis of data, interpretation of findings (ERW), conception of study objectives and/or design, interpretation of findings, revising the article for important intellectual content (TMP).

\section{References}

[1] Silberhumer GR, Paty PB, Temple LK, Araujo RL, Denton B, Gonen M, et al. Simultaneous resection for rectal cancer with synchronous liver metastasis is a safe procedure. Am J Surg 2015;209:935-942. doi: 10.1016/j.amjsurg. 2014.09.024.

[2] Spolverato G, Kim Y, Alexandrescu S, Popescu I, Marques HP, Aldrighetti L, et al. Is hepatic resection for large or multifocal intrahepatic cholangiocarcinoma justified? results from a multi-institutional collaboration. Ann Surg Oncol 2015;22:2218-2225. doi: 10.1245/s10434-014-4223-3.

[3] Imamura $H$, Seyama $Y$, Kokudo $N$, Aoki T, Sano $K$, Minagawa $M$, et al. Single and multiple resections of multiple hepatic metastases of colorectal origin. Surgery 2004;135:508-517. doi: 10.1016/j.surg.2003.10.009.

[4] Ren $Z, X u Y$, Zhu S. Indocyanine green retention test avoiding liver failure after hepatectomy for hepatolithiasis. Hepatogastroenterology 2012;59: 782-784. doi: 10.5754/hge11453.

[5] Ribeiro HS, Costa WL Jr, Diniz AL, Godoy AL, Herman P, Coudry RA, et al. Extended preoperative chemotherapy, extent of liver resection and blood transfusion are predictive factors of liver failure following resection of colorectal liver metastasis. Eur J Surg Oncol 2013;39:380-385. doi: 10.1016/j. ejso.2012.12.020

[6] van den Broek MA, Olde Damink SW, Dejong CH, Lang H, Malagó M, Jalan R, et al. Liver failure after partial hepatic resection: definition, pathophysiology, risk factors and treatment. Liver Int 2008;28:767-780. doi: $10.1111 / \mathrm{j}$. 1478-3231.2008.01777.x.

[7] Rahbari NN, Garden O], Padbury R, Brooke-Smith M, Crawford M, Adam R, et al. Posthepatectomy liver failure: a definition and grading by the International Study Group of Liver Surgery (ISGLS). Surgery 2011;149:713-724. doi: $10.1016 /$ j.surg.2010.10.001

[8] Balzan S, Belghiti J, Farges O, Ogata S, Sauvanet A, Delefosse D, et al. The "5050 criteria" on postoperative day 5: an accurate predictor of liver failure and death after hepatectomy. Ann Surg 2005;242:824-828, discussion 828-829.

[9] Mullen JT, Ribero D, Reddy SK, Donadon M, Zorzi D, Gautam S, et al. Hepatic insufficiency and mortality in 1,059 noncirrhotic patients undergoing major hepatectomy. J Am Coll Surg 2007;204:854-862; discussion 862-864. doi: 10.1016/j.jamcollsurg.2006.12.032.

[10] Rahbari NN, Reissfelder C, Koch M, Elbers H, Striebel F, Büchler MW, et al. The predictive value of postoperative clinical risk scores for outcome after hepatic resection: a validation analysis in 807 patients. Ann Surg Oncol 2011;18: 3640-3649. doi: 10.1245/s10434-011-1829-6.

[11] Kim SH, Kang DR, Lee JG, Kim DY, Ahn SH, Han KH, et al. Early predictor of mortality due to irreversible posthepatectomy liver failure in patients with hepatocellular carcinoma. World J Surg 2013;37:1028-1033. doi: 10. 1007/s00268-013-1959-z.

[12] Delis SG, Bakoyiannis A, Biliatis I, Athanassiou K, Tassopoulos N, Dervenis C. Model for end-stage liver disease (MELD) score, as a prognostic factor for post-operative morbidity and mortality in cirrhotic patients, undergoing hepatectomy for hepatocellular carcinoma. HPB (Oxford) 2009;11:351-357. doi: 10.1111/j.1477-2574.2009.00067.x.

[13] Fromer MW, Aloia TA, Gaughan JP, Atabek UM, Spitz FR. The utility of the MELD score in predicting mortality following liver resection for metastasis. Eur J Surg Oncol 2016;42:1568-1575. doi: 10.1016/j.ejso.2016.05.035.

[14] Botta F, Giannini E, Romagnoli P, Fasoli A, Malfatti F, Chiarbonello B, et al. MELD scoring system is useful for predicting prognosis in patients with liver cirrhosis and is correlated with residual liver function: a European study. Gut 2003;52:134-139. doi: 10.1136/gut.52.1.134.

[15] Huo TI, Lui WY, Wu JC, Huang YH, King KL, Loong CC, et al. Deterioration of hepatic functional reserve in patients with hepatocellular carcinoma after resection: incidence, risk factors, and association with intrahepatic tumor recurrence. World J Surg 2004;28:258-262. doi: 10.1007/s00268-0037182-6.

[16] Hyder O, Pulitano C, Firoozmand A, Dodson R, Wolfgang CL, Choti MA, et al. $A$ risk model to predict 90 -day mortality among patients undergoing hepatic resection. J Am Coll Surg 2013;216:1049-1056. doi: 10.1016/j.jamcollsurg.2013.01.004.

[17] Wiggans MG, Lordan JT, Shahtahmassebi G, Aroori S, Bowles MJ, Stell DA. The interaction between diabetes, body mass index, hepatic steatosis, and risk of liver resection: insulin dependent diabetes is the greatest risk for major complications. HPB Surg 2014;2014:586159. doi: 10.1155/2014/586159.

[18] Little SA, Jarnagin WR, DeMatteo RP, Blumgart LH, Fong Y. Diabetes is associated with increased perioperative mortality but equivalent long-term outcome after hepatic resection for colorectal cancer. J Gastrointest Surg 2002;6:88-94. doi: 10.1016/S1091-255X(01)00019-1.

[19] Amptoulach S, Gross G, Kalaitzakis E. Differential impact of obesity and diabetes mellitus on survival after liver resection for colorectal cancer metastases. J Surg Res 2015;199:378-385. doi: 10.1016/j.jss.2015.05.059.

[20] Huo TI, Lui WY, Huang YH, Chau GY, Wu JC, Lee PC, et al. Diabetes mellitus is a risk factor for hepatic decompensation in patients with hepatocellular carcinoma undergoing resection: a longitudinal study. Am J Gastroenterol 2003; 98:2293-2298. doi: 10.1111/j.1572-0241.2003.07688.x.

[21] Michalopoulos GK. Liver regeneration. J Cell Physiol 2007;213:286-300. doi: $10.1002 /$ jcp.21172.

[22] Langella S, Russolillo N, Forchino F, Lo Tesoriere R, D'Eletto M, Ferrero A. Impact of obesity on postoperative outcome of hepatic resection for colorectal metastases. Surgery 2015;158:1521-1529. doi: 10.1016/j.surg. 2015.07.024.

[23] Mathur AK, Ghaferi AA, Sell K, Sonnenday CJ, Englesbe MJ, Welling TH. Influence of body mass index on complications and oncologic outcomes following hepatectomy for malignancy. J Gastrointest Surg 2010;14:849-857. doi: 10.1007/s11605-010-1163-5.

[24] Zarzavadjian Le Bian A, Costi R, Constantinides V, Smadja C. Metabolic disorders, non-alcoholic fatty liver disease and major liver resection: an underestimated perioperative risk. J Gastrointest Surg 2012;16:2247-2255. doi: 10.1007/s11605-012-2044-x.

[25] Schindl MJ, Redhead DN, Fearon KC, Garden OJ, Wigmore SJ. The value of residual liver volume as a predictor of hepatic dysfunction and infection after major liver resection. Gut 2005;54:289-296. doi: 10.1136/gut.2004.046524.

[26] Timchenko NA. Aging and liver regeneration. Trends Endocrinol Metab 2009; 20:171-176. doi: 10.1016/j.tem.2009.01.005.

[27] Kim JM, Cho BI, Kwon CH, Joh JW, Park JB, Lee JH, et al. Hepatectomy is a reasonable option for older patients with hepatocellular carcinoma. Am J Surg 2015;209:391-397. doi: 10.1016/j.amjsurg.2013.06.010.

[28] Nanashima A, Tobinaga $S$, Abo $T$, Nonaka $T$, Takeshita $H$, Hidaka $S$, et al. Reducing the incidence of post-hepatectomy hepatic complications by preoperatively applying parameters predictive of liver function. J Hepatobiliary Pancreat Sci 2010;17:871-878. doi: 10.1007/s00534-010-0281-5.

[29] Aloia TA, Fahy BN, Fischer CP, Jones SL, Duchini A, Galati J, et al. Predicting poor outcome following hepatectomy: analysis of 2313 hepatectomies in the NSQIP database. HPB (Oxford) 2009;11:510-515. doi: 10.1111/j.14772574.2009.00095.x

[30] Tzeng CW, Cooper AB, Vauthey JN, Curley SA, Aloia TA. Predictors of morbidity and mortality after hepatectomy in elderly patients: analysis of 7621 NSQIP patients. HPB (Oxford) 2014;16:459-468. doi: 10.1111/hpb.12155.

[31] Fan ST, Lo CM, Lai EC, Chu KM, Liu CL, Wong J. Perioperative nutritional support in patients undergoing hepatectomy for hepatocellular carcinoma. N Engl J Med 1994;331:1547-1552. doi: 10.1056/NEJM199412083312303.

[32] Kim BJ, Tzeng CD, Cooper AB, Vauthey JN, Aloia TA. Borderline operability in hepatectomy patients is associated with higher rates of failure to rescue after 
severe complications. J Surg Oncol 2017:115:337-343. doi: 10.1002/jso. 24506.

[33] Bismuth H, Houssin D, Ornowski J, Meriggi F. Liver resections in cirrhotic patients: a Western experience. World J Surg 1986;10:311-317. doi: 10. 1007/BF01658152.

[34] Gozzetti G, Mazziotti A, Cavallari A, Bellusci R, Bolondi L, Grigioni W, et al. Clinical experience with hepatic resections for hepatocellular carcinoma in patients with cirrhosis. Surg Gynecol Obstet 1988;166:503-510.

[35] Garcea G, Maddern GJ. Liver failure after major hepatic resection. J Hepatobiliary Pancreat Surg 2009;16:145-155. doi: 10.1007/s00534-008-0017-y.

[36] de Meijer VE, Kalish BT, Puder M, Ijzermans JN. Systematic review and metaanalysis of steatosis as a risk factor in major hepatic resection. $\mathrm{Br}$ J Surg 2010;97:1331-1339. doi: 10.1002/bjs.7194.

[37] Reddy SK, Marsh JW, Varley PR, Mock BK, Chopra KB, Geller DA, et al. Underlying steatohepatitis, but not simple hepatic steatosis, increases morbidity after liver resection: a case-control study. Hepatology 2012;56:2221-2230. doi: $10.1002 /$ hep. 25935 .

[38] Vauthey JN, Pawlik TM, Ribero D, Wu TT, Zorzi D, Hoff PM, et al. Chemotherapy regimen predicts steatohepatitis and an increase in 90-day mortality after surgery for hepatic colorectal metastases. J Clin Oncol 2006;24:20652072. doi: 10.1200/JCO.2005.05.3074.

[39] Robinson SM, Wilson CH, Burt AD, Manas DM, White SA. Chemotherapyassociated liver injury in patients with colorectal liver metastases: a systematic review and meta-analysis. Ann Surg Oncol 2012;19:4287-4299. doi: 10.1245/s10434-012-2438-8.

[40] Tevar AD, Clarke C, Wang J, Rudich SM, Woodle ES, Lentsch AB, et al. Clinical review of nonalcoholic steatohepatitis in liver surgery and transplantation. J Am Coll Surg 2010;210:515-526. doi: 10.1016/j.jamcollsurg.2010.01.020.

[41] Narita M, Oussoultzoglou E, Chenard MP, Rosso E, Casnedi S, Pessaux P, et al. Sinusoidal obstruction syndrome compromises liver regeneration in patients undergoing two-stage hepatectomy with portal vein embolization. Surg Today 2011;41:7-17. doi: 10.1007/s00595-010-4414-x.

[42] Iacono C, Ruzzenente A, Campagnaro T, Bortolasi L, Valdegamberi A, Guglielmi A. Role of preoperative biliary drainage in jaundiced patients who are candidates for pancreatoduodenectomy or hepatic resection: highlights and drawbacks. Ann Surg 2013;257:191-204. doi: 10.1097/SLA. Ob013e31826f4b0e.

[43] Kloek J], Levi M, Heger M, van der Loos CM, Gouma DJ, van Gulik TM. Cholestasis enhances liver ischemia/reperfusion-induced coagulation activation in rats. Hepatol Res 2010;40:204-215. doi: 10.1111/j.1872-034X.2009. 00579.x.

[44] Mansour JC, Aloia TA, Crane CH, Heimbach JK, Nagino M, Vauthey JN. Hilar cholangiocarcinoma: expert consensus statement. HPB (Oxford) 2015;17: 691-699. doi: 10.1111/hpb.12450.

[45] Olthof PB, Wiggers JK, Groot Koerkamp B, Coelen RJ, Allen PJ, Besselink MG, et al. Postoperative liver failure risk score: identifying patients with resectable perihilar cholangiocarcinoma who can benefit from portal vein embolization. J Am Coll Surg 2017;225:387-394. doi: 10.1016/j.jamcollsurg. 2017.06.007.

[46] Watanabe K, Yokoyama $Y$, Kokuryo T, Kawai K, Kitagawa T, Seki T, et al. Segmental cholangitis impairs hepatic regeneration capacity after partial hepatectomy in rats. HPB (Oxford) 2010;12:664-673. doi: $10.1111 / \mathrm{j}$. 1477-2574.2010.00229.x.

[47] Yokoyama Y, Ebata T, Igami T, Sugawara G, Mizuno T, Nagino M. The adverse effects of preoperative cholangitis on the outcome of portal vein embolization and subsequent major hepatectomies. Surgery 2014;156:1190-1196. doi: 10.1016/j.surg.2014.04.036.

[48] Melendez J, Ferri E, Zwillman M, Fischer M, DeMatteo R, Leung D, et al. Extended hepatic resection: a 6 -year retrospective study of risk factors for perioperative mortality. J Am Coll Surg 2001;192:47-53.

[49] Tomuş C, Iancu C, Bălă O, Graur F, Furcea L, Zaharie F, et al. Liver resection for benign hepatic lesion: mortality, morbidity and risk factors for postoperative complications. Chirurgia (Bucur) 2009;104:275-280.

[50] Imamura H, Seyama Y, Kokudo N, Maema A, Sugawara $Y$, Sano K, et al. One thousand fifty-six hepatectomies without mortality in 8 years. Arch Surg 2003; 138:1198-1206; discussion 1206. doi: 10.1001/archsurg.138.11.1198.

[51] Vauthey JN, Chaoui A, Do KA, Bilimoria MM, Fenstermacher MJ, Charnsangavej $C$, et al. Standardized measurement of the future liver remnant prior to extended liver resection: methodology and clinical associations. Surgery 2000;127:512-519. doi: 10.1067/msy.2000.105294.

[52] Kishi Y, Abdalla EK, Chun YS, Zorzi D, Madoff DC, Wallace MJ, et al. Three hundred and one consecutive extended right hepatectomies: evaluation of outcome based on systematic liver volumetry. Ann Surg 2009;250:540548. doi: 10.1097/SLA.0b013e3181b674df.

[53] Tomimaru Y, Eguchi H, Gotoh K, Kawamoto K, Wada H, Asaoka T, et al. Platelet count is more useful for predicting posthepatectomy liver failure at surgery for hepatocellular carcinoma than indocyanine green clearance test. J Surg Oncol 2016;113:565-569. doi: 10.1002/jso.24166.

[54] Panicek DM, Giess CS, Schwartz LH. Qualitative assessment of liver for fatty infiltration on contrast-enhanced CT: is muscle a better standard of reference than spleen? J Comput Assist Tomogr 1997;21:699-705. doi: 10.1097/00004728-199709000-00004.

[55] Shoup M, Gonen M, D'Angelica M, Jarnagin WR, DeMatteo RP, Schwartz LH, et al. Volumetric analysis predicts hepatic dysfunction in patients undergoing major liver resection. J Gastrointest Surg 2003;7:325-330. doi: 10. 1016/S1091-255X(02)00370-0.

[56] Fan ST. Liver functional reserve estimation: state of the art and relevance for local treatments: the Eastern perspective. J Hepatobiliary Pancreat Sci 2010; 17:380-384. doi: 10.1007/s00534-009-0229-9.

[57] Zipprich A, Kuss O, Rogowski S, Kleber G, Lotterer E, Seufferlein T, et al. Incorporating indocyanin green clearance into the Model for End Stage Liver Disease (MELD-ICG) improves prognostic accuracy in intermediate to advanced cirrhosis. Gut 2010;59:963-968. doi: 10.1136/gut.2010.208595.

[58] Vos J], Wietasch JK, Absalom AR, Hendriks HG, Scheeren TW. Green light for liver function monitoring using indocyanine green? An overview of current clinical applications. Anaesthesia 2014;69:1364-1376. doi: 10.1111/anae. 12755.

[59] Halle BM, Poulsen TD, Pedersen HP. Indocyanine green plasma disappearance rate as dynamic liver function test in critically ill patients. Acta Anaesthesiol Scand 2014;58:1214-1219. doi: 10.1111/aas.12406.

[60] Mizuguchi T, Kawamoto M, Meguro M, Hui TT, Hirata K. Preoperative liver function assessments to estimate the prognosis and safety of liver resections. Surg Today 2014;44:1-10. doi: 10.1007/s00595-013-0534-4.

[61] Fan ST, Lai EC, Lo CM, Ng IO, Wong J. Hospital mortality of major hepatectomy for hepatocellular carcinoma associated with cirrhosis. Arch Surg 1995; 130:198-203. doi: 10.1001/archsurg.1995.01430020088017.

[62] Imamura H, Sano K, Sugawara $Y$, Kokudo N, Makuuchi M. Assessment of hepatic reserve for indication of hepatic resection: decision tree incorporating indocyanine green test. J Hepatobiliary Pancreat Surg 2005;12:16-22. doi: 10.1007/s00534-004-0965-9.

[63] Yoshida M, Beppu T, Shiraishi S, Tsuda N, Sakamoto F, Okabe H, et al. (99m) TC-GSA SPECT/CT fused images for assessment of hepatic function and hepatectomy planning. Ann Transl Med 2015;3:17. doi: 10.3978/j.issn.23055839.2014.12.11.

[64] Nakagawa M, Namimoto T, Shimizu K, Morita K, Sakamoto F, Oda S, et al. Measuring hepatic functional reserve using T1 mapping of Gd-EOB-DTPA enhanced 3T MR imaging: A preliminary study comparing with $99 \mathrm{mTC}$ GSA scintigraphy and signal intensity based parameters. Eur J Radiol 2017;92: 116-123. doi: 10.1016/j.ejrad.2017.05.011.

[65] Costa AF, Tremblay St-Germain A, Abdolell M, Smoot RL, Cleary S, Jhaveri KS. Can contrast-enhanced MRI with gadoxetic acid predict liver failure and other complications after major hepatic resection? Clin Radiol 2017;72:598605. doi: 10.1016/j.crad.2017.02.004.

[66] Abdalla EK, Denys A, Chevalier P, Nemr RA, Vauthey JN. Total and segmental liver volume variations: implications for liver surgery. Surgery 2004;135: 404-410. doi: 10.1016/j.surg.2003.08.024.

[67] Vauthey JN, Abdalla EK, Doherty DA, Gertsch P, Fenstermacher MJ, Loyer EM, et al. Body surface area and body weight predict total liver volume in Western adults. Liver Transpl 2002;8:233-240. doi: 10.1053/jlts.2002.31654.

[68] Abdalla EK, Adam R, Bilchik AJ, Jaeck D, Vauthey JN, Mahvi D. Improving resectability of hepatic colorectal metastases: expert consensus statement. Ann Surg Oncol 2006;13:1271-1280. doi: 10.1245/s10434-006-9045-5.

[69] Zorzi D, Laurent A, Pawlik TM, Lauwers GY, Vauthey JN, Abdalla EK. Chemotherapy-associated hepatotoxicity and surgery for colorectal liver metastases. Br J Surg 2007;94:274-286. doi: 10.1002/bjs.5719.

[70] Shindoh J, Truty MJ, Aloia TA, Curley SA, Zimmitti G, Huang SY, et al. Kinetic growth rate after portal vein embolization predicts posthepatectomy outcomes: toward zero liver-related mortality in patients with colorectal liver metastases and small future liver remnant. J Am Coll Surg 2013;216:201209. doi: 10.1016/j.jamcollsurg.2012.10.018.

[71] Yamashita S, Shindoh J, Mizuno T, Chun YS, Conrad C, Aloia TA, et al. Hepatic atrophy following preoperative chemotherapy predicts hepatic insufficiency after resection of colorectal liver metastases. J Hepatol 2017;67:56-64. doi: 10.1016/j.jhep.2017.01.031.

[72] Kauffmann R, Fong Y. Post-hepatectomy liver failure. Hepatobiliary Surg Nutr 2014;3:238-246. doi: 10.3978/j.issn.2304-3881.2014.09.01.

[73] Finch RJ, Malik HZ, Hamady ZZ, Al-Mukhtar A, Adair R, Prasad KR, et al. Effect of type of resection on outcome of hepatic resection for colorectal metastases. Br J Surg 2007;94:1242-1248. doi: 10.1002/bjs.5640.

[74] Lordan JT, Roberts JK, Hodson J, Isaac J, Muiesan P, Mirza DF, et al. Casecontrolled study comparing peri-operative and cancer-related outcomes after major hepatectomy and parenchymal sparing hepatectomy for metastatic colorectal cancer. HPB (Oxford) 2017;19:688-694. doi: 10.1016/j. hpb.2017.04.007.

[75] Memeo R, de Blasi V, Adam R, Goéré D, Azoulay D, Ayav A, et al. Parenchymalsparing hepatectomies (PSH) for bilobar colorectal liver metastases are associated with a lower morbidity and similar oncological results: a propensity score matching analysis. HPB (Oxford) 2016;18:781-790. doi: 10 . 1016/j.hpb.2016.06.004. 
Rahnemai-Azar A.A. et al: Prevention of post-hepatectomy liver failure

[76] Alvarez FA, Sanchez Claria R, Oggero S, de Santibañes E. Parenchymalsparing liver surgery in patients with colorectal carcinoma liver metastases. World J Gastrointest Surg 2016;8:407-423. doi: 10.4240/wjgs.v8.i6.407.

[77] Abdalla EK. Portal vein embolization (prior to major hepatectomy) effects on regeneration, resectability, and outcome. J Surg Oncol 2010;102:960-967. doi: $10.1002 /$ jso.21654.

[78] Ribero D, Abdalla EK, Madoff DC, Donadon M, Loyer EM, Vauthey JN. Portal vein embolization before major hepatectomy and its effects on regeneration, resectability and outcome. Br J Surg 2007;94:1386-1394. doi: 10.1002/bjs.5836.

[79] Schadde E, Ardiles V, Robles-Campos R, Malago M, Machado M, HernandezAlejandro $R$, et al. Early survival and safety of ALPPS: first report of the International ALPPS Registry. Ann Surg 2014;260:829-836; discussion 836-838. doi: 10.1097/SLA.0000000000000947.

[80] de Santibañes E, Clavien PA. Playing Play-Doh to prevent postoperative liver failure: the "ALPPS" approach. Ann Surg 2012;255:415-417. doi: 10 1097/SLA.0b013e318248577d.

[81] Makuuchi M, Thai BL, Takayasu K, Takayama T, Kosuge T, Gunvén P, et al. Preoperative portal embolization to increase safety of major hepatectomy for hilar bile duct carcinoma: a preliminary report. Surgery 1990;107:521-527.

[82] Abdalla EK, Hicks ME, Vauthey JN. Portal vein embolization: rationale, technique and future prospects. Br J Surg 2001;88:165-175. doi: 10.1046/j. 1365-2168.2001.01658.x
[83] Madoff DC, Abdalla EK, Gupta S, Wu TT, Morris JS, Denys A, et al. Transhepatic ipsilateral right portal vein embolization extended to segment IV: improving hypertrophy and resection outcomes with spherical particles and coils. J Vasc Interv Radiol 2005;16:215-225. doi: 10.1097/01.RVI 0000147067.79223 .85

[84] Wilms C, Mueller L, Lenk C, Wittkugel O, Helmke K, Krupski-Berdien G, et al. Comparative study of portal vein embolization versus portal vein ligation for induction of hypertrophy of the future liver remnant using a mini-pig model. Ann Surg 2008;247:825-834. doi: 10.1097/SLA.0b013e31816a9d7c.

[85] Schnitzbauer AA, Lang SA, Goessmann H, Nadalin S, Baumgart J, Farkas SA, et al. Right portal vein ligation combined with in situ splitting induces rapid left lateral liver lobe hypertrophy enabling 2-staged extended right hepatic resection in small-for-size settings. Ann Surg 2012;255:405-414. doi: 10. 1097/SLA.0b013e31824856f5.

[86] van Mierlo KM, Schaap FG, Dejong CH, Olde Damink SW. Liver resection for cancer: New developments in prediction, prevention and management of postresectional liver failure. J Hepatol 2016;65:1217-1231. doi: 10.1016/j. jhep.2016.06.006.

[87] Wang YY, Zhong JH, Su ZY, Huang JF, Lu SD, Xiang BD, et al. Albumin-bilirubin versus Child-Pugh score as a predictor of outcome after liver resection for hepatocellular carcinoma. Br J Surg 2016;103:725-734. doi: 10.1002/ bjs. 10095 . 